\title{
Preventing Inguinodynia After Hernia Surgery: Does the Type of Mesh Matter?
}

\author{
Nehal Sureshkumar Shah $\cdot$ Aali Sheen
}

Published online: 5 November 2014

(C) Société Internationale de Chirurgie 2014

To the editor,

We, the authors, read with interest the comments from Pellino and Selvaggi on our article [1]. We agree with the observation from Pellino et al. and colleagues that surgical expertise, method of mesh fixation as well as type of mesh used is likely to be the determining factor in post-operative chronic pain [2]. It is though mooted but remains to be demonstrated in any randomized controlled trial as to whether a patient's relative weight and body mass index may determine mesh comfort, especially as 'thin' patients may more inclined to experience a foreign body sensation? Our study does demonstrate that fixation is a key factor with traumatic fixation being more inclined to result in increased post-operative discomfort. Further work is still required with trials aiming at long-term follow-up, however from previous studies and experience it would seem reasonable to predict that long-term follow-up may show little significant difference [3].

\section{References}

1. Shah NS, Fullwood C, Siriwardena AK, Sheen AJ (2014) Mesh fixation at laparoscopic inguinal hernia repair: a meta-analysis comparing fibrin glue to tack fixation. World J Surg. doi:10.1007/ s00268-014-2547-6

2. Bittner R, Leibl BJ, Kraft B, Schwarz J (2011) One-year results of a prospective, randomised clinical trial comparing four meshes in laparoscopic inguinal hernia repair (TAPP). Hernia 15(5):503-510. doi:10.1007/s10029-011-0810-4

3. Nikkolo C, Murruste M, Vaasna T, Seepter H, Tikk T, Lepner U (2012) Three-year results of randomised clinical trial comparing lightweight mesh with heavyweight mesh for inguinal hernioplasty. Hernia 16(5):555-559. doi:10.1007/s10029-012-0951-0 